\title{
Pragmatic Review of Literature Associated with Projectile Motion Perceived as Difficult to Teach by Some South African Teachers
}

\author{
Awelani V. Mudau \\ Department of Science and Technology Education, \\ University of South Africa, South Africa \\ Mudauav@unisa.ac.za
}

\section{Doi:10.5901/mjss.2014.v5n8p441}

\section{Abstract}

The paper presents a literature review on the topic projectile motion in high schools. The review focused on empirical studies aiming on the development of the concept as well as those that identified and explored misconceptions associated with the topic. Furthermore, studies that presented the strategies to deal with misconception in projectile motion and the necessary prior knowledge that can be a pre-requisite are discussed. The context of the topic in the NCS is also discussed as well as the challenges associated with its learning from the DBE perspective. The paper concludes with what could be the gaps and prospects of the literature reviewed on the topic projectile motion.

Keywords: projectile motion, prior knowledge, STEM, misconceptions, performance

\section{Introduction and Background}

In accomplishing the expectations of the $21^{\text {st }}$ century and the South African government at large, it is appropriately vital that the focus of learner performance is largely on the subjects that will qualify them to opt for carriers in the science, technology, engineering and mathematics (STEM) field. Yet, learner performance in physical science is not yet at a desired state. Consequently, the Department of Basic Education (DBE) in South Africa analysed the results to determine the reasons for the poor performance. Projectile motion was identified as one of the topics in which students performed the worst (DBE, 2011). Further analysis on the learner responses on the topic showed that,

There is a serious lack of mathematical skills like interpretation and drawing of graphs, solving equations and working with trigonometric ratios. It is also clearly evident that most learners [students] have little or no problem-solving skills. Most learners [students] cannot grapple with problems. Many learners [students] stopped midway in their answers that involved calculations, possibly due to having no calculators or not having the necessary skills to use the calculators. (DBE, 2011:117)

Though the questions were testing critical thinking and problem solving skills (DBE, 2011), the above findings were unexpected as many of the questions were only on level two and three in Bloom's taxonomy (DBE, 2011). Additionally, they showed the common mistakes students make in answering projectile motion and those are listed in Table 1 (DBE, 2011 and 2010). These are the mistakes that were identified from students' responses from 2008 until 2010 (DBE, 2011).

Table 1: Students' mistakes in projectile motion

\footnotetext{
-Students are not explicitly taught when to use $\Delta \mathrm{x}$ and $\Delta \mathrm{y}$ and they do not correctly transfer the equation from the data sheet to their answer sheet.

-Students confuse the sign for an upward and downward motion.

-The interpretation of the positive and negative sign for the final answer in a calculation is not done by students.

-Easier ways of doing calculation not taught to students.

-Teachers use the methods they like, not thinking about how effective it is for the level of students.

-Students do not isolate the data given and then choose an appropriate formula to calculate the answer.

-Students cannot explain the reasons for the different shapes in graphs.

-Students have problems with linking the different parts of the graph with the actual motion and exact positions on the $\mathrm{x}$ and $\mathrm{y}$ axis.

-Students still cannot choose appropriate equations of motion for calculations involving horizontal and vertical motion.

-Students still cannot manipulate the formula.

-Students lose a lot of marks for mixing up $v_{f}$ and $v_{i}$ as well as the + and - sign.

-Students copying the formula incorrectly from the data sheet.
} 
The DBE suggested the following recommendations to improve the performance in the topic (DBE, 2011:121):

1. Greater emphasis should be placed on the drawing and interpretation of graphs of motion in class;

2. Teachers should cover more examples of vertical projectile motion in their teaching. They should use examples of the application of the concepts of inertia and Newton's 1st law when teaching these concepts;

3. Students should be taught to indicate their chosen sign convention at the beginning of the problem.

The challenges shown by the DBE which contribute to the poor performance in projectile motion in particular and Physical Science at large put the responsibility largely on the students. However, the students' mistakes (Table 1) are worded such that one can infer that students are committing them because of how they were taught. Yet, what teachers do when teaching the topic is only referred to once when they state that teachers use their own preferred methods without evaluating their effectiveness. This statement is loaded in that it does not specifically indicate what those methods are. As such the insinuation by the DBE is that students are responding as such due to how they were taught by teachers. Nonetheless, not much is unpacked as to what is it which teachers do during teaching besides just saying that they use their own preferred methods.

From the teachers perspectives some Grade 12 Physical Science teachers in the Johannesburg Central district of education in Gauteng Province, South Africa, had a perception that projectile motion is difficult to teach, hence the students' poor performance in the topic (Mudau, Mundalamo and Sedumedi, 2013). In fact, from the discussions and comments at the Grade 12 examinations marking sessions of the Gauteng Province since 2006, projectile motion has always been one of the topics identified as contributing to poor performance. The question that can be asked is what is it that teachers are doing in the classrooms which makes them perceive the topic to be difficult to teach and why do they perceive the topic to be difficult to teach.

The government and research institutions are engaged with studies to diagnose the impediments. For those that are known, strategies are designed and/or put in place to remedy the impediments. However, this is not a once off event but rather on-going. As such it is the purpose of this paper to bring to forth some perspective on one of the physics topic which is perceived to be difficult to teach. This should build into the fundamentals to explore and investigate factors influencing performance as well as the kind of in-service training teachers may need.

\section{Projectile Motion in the NCS}

In the South African schooling context and the Physical Science framework (GDE, 2010) projectile motion as a concept is developed from Grade 10. The Grade 10-12 phase is made up of different subjects with unique subject frameworks. The framework contains the themes and concepts that students have to learn in a particular subject in the FET band. The Physical Science subject framework is made up of six knowledge areas, namely Mechanics, Waves, Sound and Light, Electricity and Magnetism, Matter and Materials, Chemical Change and Chemical Systems. Projectile motion is part of the knowledge area Mechanics. The following are the topics that make up Mechanics at Grade 12: projectile motion, projectile motion in two dimensions, the conservation of momentum in two dimensions, impulse and change in momentum, elastic and inelastic collision and frames of reference.

In Grade 10, students are expected to learn about speed, displacement, distance, position, velocity and acceleration. They also learn to describe motion in words, diagrams and graphs. In Grade 10 the graphs generally apply to horizontal motion in one dimension. The concepts of gravitational acceleration and free fall are dealt with briefly and equations of motion are also introduced. In Grade 11, students are expected to learn different types of forces and learn Newton's laws of motion. In Grade 12 students learn projectile motion represented in words, diagrams, equations and graphs. They also learn vertical projectile motion and projectile motion in two dimensions.

\section{Empirical Studies on Projectile Motion}

The study of motion of objects is part of the field of mechanics (Giancoli, 1998), which is divided into kinematics and dynamics. Kinematics describes how objects move whilst dynamics focuses on the force and why objects move as they do. Translational motion is part of kinematics, which is the motion of an object that is moving without rotating and can be described in terms of one, or two or three dimensions. Projectile motion is a translational motion, which is motion in two dimensions. Gilbert and Zylbersztajn (1985) define a projectile as a body that is projected through a gravitational field. They further indicate that it can be thrown straight up or down. This type of motion is known as vertical projectile motion. If the projectile is thrown at an angle to the ground (horizontal) it results in projectile motion in two dimensions. In projectile motion the force of gravity is the only force acting on the body and therefore the object is in free fall.

Many studies have been conducted on projectile motion. Some studies were focused on the development of the 
concept of projectile motion to locate possible origins of misconceptions (Gilbert \& Zylbersztajn, 1985). Some were focused on identifying misconceptions from students and teachers (Bayraktar, 2009 and Prescott \& Mitchelmore, 2005). Other studies focused on the strategies of teaching projectile motion, many of which were suggesting the use of conceptual change theory (Dilber, Karaman \& Duzgun, 2009 and Hlatshwayo, 2006). Some refuted the claim that conceptual change can be a solution (Graham, Berry \& Rowlands, 2012).

The study by Gilbert and Zylbersztajn (1985) discussed the conceptual framework for science education in respect of force and movement with a focus on scientist science, children science and curricular science. The framework is illustrated in Figure 1. The scientist science showed the development of the understanding of force and movement and how scientists understood projectile motion over time from the days of Aristotle through the times of impetus theory and lastly the perspectives of Galileo and Newton. In children science they showed that pre-Galilean ideas about projectile motion were prevalent among school children and in some cases still persisted even after formal years of physics teaching. The researcher agrees with their assertion about children science as it was evident during his teaching experience. Students in a Grade 12 class would say that there is a force pushing the ball if it is rolling. Furthermore, some would say an object thrown upwards falls because the upward force is used up.

Figure 1: Force and motion conceptual framework

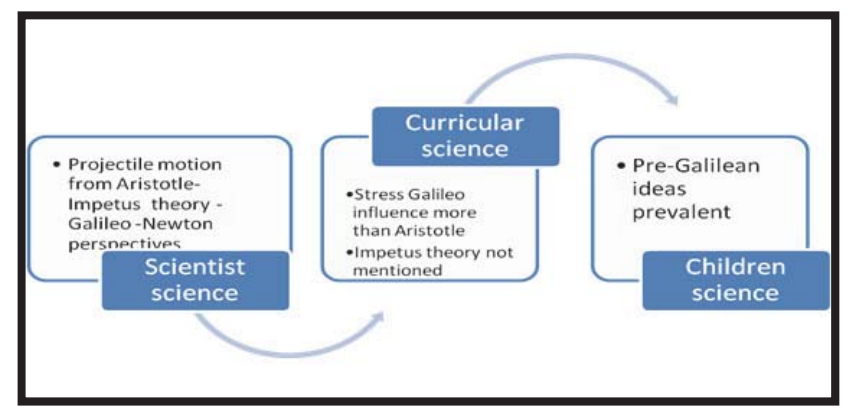

As illustrated in Figure 1, in curricular science Gilbert and Zylbersztajn (1985) showed that the impetus theory is not mentioned at all, a point also apparent in the NCS. They concluded by indicating that the omission of impetus theory in the curricular science has detrimental effects. This is so because they found that children science had a lot of alternative conceptions based on impetus theory and they suggested that if teachers were made to pay more attention to the alternative conceptions it would assist in the teaching and learning of projectile motion. This point was also recommended by Hlatshwayo (2006).

Different studies were conducted to identify misconceptions held by students (Table 1). In the South African context a study by Hlatshwayo (2006) found that Grade 12 students had more misconceptions than Grade 11 students in the area of projectile motion. A reason for this was that Grade 11 students had the most recent prior knowledge relevant to learning projectile motion whilst their counterparts had been taught the previous year. Table 1 below summarises the common misconceptions identified from some of the studies.

Table 1: Some of the misconceptions in projectile motion

\begin{tabular}{|l|l|}
\hline Misconception & Explanation \\
\hline $\begin{array}{l}\text { Acceleration and velocity are always in the same direction } \\
\text { (Rosenquist \& McDermott, 1987). }\end{array}$ & $\begin{array}{l}\text { Velocity and acceleration are not necessarily in the same } \\
\text { direction. The velocity of a ball that is moving upward is positive } \\
\text { (upward is positive) whereas its acceleration is negative. }\end{array}$ \\
\hline $\begin{array}{l}\text { An object thrown upward has zero acceleration at the highest point } \\
\text { (Whitaker, 1983). }\end{array}$ & At the highest point gravity does not stop acting. \\
\hline $\begin{array}{l}\text { A fired object requires an impetus to keep the object travelling } \\
\text { forward and as the impetus is used up gravity takes place and the } \\
\text { object falls to the ground (Prescott \& Mitchelmore, 2005). }\end{array}$ & $\begin{array}{l}\text { An external force is required to change motion, not to sustain it. } \\
\text { Hence only the force of gravity is acting on the fired object. }\end{array}$ \\
\hline $\begin{array}{l}\text { A body moving at high velocity has high acceleration and a body } \\
\text { moving at low velocity has low acceleration (Whitaker, 1983). }\end{array}$ & $\begin{array}{l}\text { High velocity does not mean high acceleration. Acceleration can } \\
\text { be high, low or zero in high velocities. It is only related to the } \\
\text { change in velocity. }\end{array}$ \\
\hline
\end{tabular}




\begin{tabular}{|l|l|}
\hline Misconception & Explanation \\
\hline $\begin{array}{l}\text { Dropped objects from a moving carrier fall straight down or move } \\
\text { backwards (Millar \& Kragh, 1994). }\end{array}$ & $\begin{array}{l}\text { Released objects initially have the same forward motion as the } \\
\text { carrier. }\end{array}$ \\
\hline $\begin{array}{l}\text { Force is a kind of fuel or energy that sustains motion but at the } \\
\text { same time it is consumed by the motion itself (Tao \& Gunstone, } \\
\text { 1999). }\end{array}$ & $\begin{array}{l}\text { Force does not sustain motion and only the external force is } \\
\text { required to change motion. }\end{array}$ \\
\hline $\begin{array}{l}\text { An increase in force will increase speed (Prescott \& Mitchelmore, } \\
\text { 2005). }\end{array}$ & $\begin{array}{l}\text { Acceleration is directly proportional to the net force. Increase in } \\
\text { force does not necessarily result in an increase in speed. } \\
\text { Acceleration is related to the change in velocity. }\end{array}$ \\
\hline Gravity is the result of air pressure (Vosniadou, 1994). & Gravity is a force independent of air resistance. \\
\hline Gravity is the property of the object itself (Vosniadou, 1994). & Gravity is external force acting on the object. \\
\hline
\end{tabular}

There have also been studies that focused on teachers teaching projectile motion, for example those by Bayraktar (2009); Prescott and Mitchelmore (2005) and Prescott (2004). The study by Bayraktar (2009) showed misconceptions held by teachers and also claimed that teachers' misconceptions were likely to be transferred to the students. The studies by Prescott and Mitchelmore (2005) and Prescott (2004) investigated if teachers also had misconceptions similar to those of their students and if so, how those misconceptions affected their teaching. It was found that the teachers reinforced the misconceptions held by students without noticing that they were reinforcing them. The teachers also indicated that they limited discussions about projectile motion and spent more time on calculations.

Because the topic of projectile motion is challenging to some teachers and students, many studies have focused on the strategies for teaching and learning projectile motion. For example, the study by Eckstein (1997) focused on how children learn projectile motion, while the study by Tao and Gunstone (1999) focused on using computer-supported Physics instruction to bring conceptual change in projectile motion. Park and Han (2002) showed how to use deductive reasoning to teach projectile motion. A study by Dilber et al. (2009) also investigated the use of conceptual change based instruction to improve students' understanding of projectile motion. Davies and McMahon (2004) researched developing continuity and progression between primary and secondary science education to try to improve the comprehension of the subject matter. Bayraktar (2009) suggested that effective strategies must be used to teach the content but was not specific on which teaching strategies.

A study by Graham et al. (2012) showed that conceptual change cannot be the solution as children do not always bring misconceptions to the classroom. Some students' misconceptions are created whilst the teacher is teaching the concept. Thus strategies based on conceptual change theory cannot be the absolute solution. Even though the intervention by Prescott and Mitchelmore (2005) was successful to a certain extent not many studies have embarked on investigating further how teachers can be assisted in practice besides offering strategies. Taking into consideration the studies by Bayraktar (2009), Prescott and Mitchelmore (2005), and Prescott (2004), there is a need to focus on classroom practices to help the teacher to teach in such a way that students comprehend the subject matter.

\section{Prior Knowledge in the Teaching of Projectile Motion}

In the teaching of projectile motion, science teachers should be aware that students' learning capabilities depend heavily on their prior knowledge and experiences (Eryilmaz, 2002 and Hausfather, 2001). The researcher agrees with this notion because learning is a purposeful, internal, mental process that is fundamentally influenced by the student's prior knowledge (Staver, 2007). Furthermore, science teachers are encouraged to consider the complex interactions between students' prior knowledge and experiences as well as reasoning abilities (Staver, 2007). This is so because according to Hausfather (2001:16) "learning involves continually connecting prior knowledge with new information and it can facilitate, inhibit, or transform learning". Therefore prior knowledge in projectile motion and experiences should be considered in Grade 12. Hlatshwayo (2006) and Galus (2002) argue that it is very important for students to have learnt and understood Newton's laws before engaging with projectile motion. Galus (2002:48) also raises an important issue, namely that:

\footnotetext{
.... challenge faced by physical science teachers is inspiring students to not just memorize, but also apply what they learned about these laws to any moving object.
}

Galus (2002) further proposes that knowledge of motion in one dimension is essential prior to the teaching of projectile motion. From one dimensional motion, the following aspects should be considered: how fast an object is moving; the direction, which is called velocity, and change in velocity in a given time, namely acceleration. Knowledge of free fall is also important as it enables students to explain acceleration due to gravity. The use of general kinematics 
equations for constant acceleration is also considered. What Staver (2007), Hlatshwayo (2006), Galus (2002) and Eryilmaz (2002) have raised are plausible suggestions, taking into consideration the idea of Gilbert and Zylbersztajn (1985) that impetus theoretical perspectives and Aristotelian ideas still manifest in students because of the focus of the science curriculum. What the international research has suggested is exactly how the concept in the South African context has been outlined. Students require the prior knowledge gained from Grade 10 as well as other outside experiences to learn projectile motion at Grade 12. It is up to the science teacher to connect science concepts and instructions explicitly to students' personal and prior experiences of projectile motion for learning to be meaningful (Staver, 2007). Science teachers should employ teaching strategies that help students recognize conflicts and inconsistencies in their thinking as they catalyse the construction of new and more coherent knowledge.

\section{Conclusion}

The review in this paper has shown that there has been more emphasis on studies of students and their learning. For example, many studies on motion and projectile motion in particular were about identifying misconceptions as well as teaching strategies to replace those misconceptions. These studies did not focus on teachers' classroom practices as a reflection of their knowledge that includes instructional strategies, interactions and discourse in the classroom. What teachers do when they teach particular subject matter knowledge is fundamental to student learning. The possession of relevant content knowledge is only part of the teaching story; effective teaching skills are fundamental to the story too.

\section{References}

Bayraktar, S. (2009). Misconceptions of Turkish pre-service teachers about force and motion. International Journal of Science and Mathematics Education, 7, 273-291.

Department of Basic Education. (2010). Road show reports. Pretoria: Department of Basic Education.

Department of Basic Education. (2011). National diagnostic reports on learner performance. Pretoria: Department of Basic Education.

Dilber, R., Karaman, I., and Duzgun, B. (2009). High school students' understanding of projectile motion concepts. Educational Research and Evaluation, 15(3), 203-222.

Eckstein, S.G. (1997). Parallelism in the development of children's ideas and the historical development of projectile motion theories. International Journal of Science Education, 19(9), 1057-1073.

Eryilmaz, A. (2002). Effects of conceptual assignments and conceptual change discussion on students' misconceptions and achievement regarding forces and motion. Journal of Research in Science Teaching, 39(10), 1001-1015.

Galus, P.J. (2002). Toying with motion. The Physics Teacher, 69(4), 48-51.

Gauteng Department of Education. (2010). Physical Science subject framework. Johannesburg: Gauteng Department of Education documents.

Giancoli, D.C. (1998). Physics: principles with applications. $5^{\text {th }}$ ed. Englewood Cliffs, NJ: Prentice Hall.

Gilbert, H.K. and Zylbersztajn, A. (1985). A conceptual framework for science education: the case study of force and movement. European Journal of Science Education, 7(2), 107-120.

Graham, T., Berry, J. and Rowlands, S. (2012). Are 'misconceptions' or alternative frameworks of force and motion spontaneous or formed prior to instruction? International Journal of Mathematical Education in Science and Technology, (24 July 2012), 1-20.

Gunstone, R., Mulhall, P. and McKittrick, B. (2009). Physics teachers' perceptions of the difficulty of teaching electricity. Research in Science Education, (39), 515-538.

Hlatshwayo, E.S.E. (2006). Alternative conception of high school science students on projectile motion. Unpublished MSc dissertation. Johannesburg: University of the Witwatersrand.

Park, J. and Han, S. (2002). Using deductive reasoning to promote the change of students' conceptions about force and motion. International Journal of Science Education, 24(6), 539-609.

Prescott, A. and Mitchelmore, M. (2005) Teaching projectile motion to eliminate misconceptions. In: H.L. Chick, and J.L. Vincent, eds. Proceedings of the 29th Conference of the International Group for the Psychology of Mathematics Education, 4, 97-104.

Prescott, A.E. (2004). Student understanding and learning about projectile motion in senior high school. Unpublished doctoral thesis. Macquarie University, Sydney.

Rosenquist, M.L. and McDermott, L.C. (1987). A conceptual approach to teaching mechanics. American Journal of Physics, 55, 407-415.

South African Qualifications Authority, (2012). Level descriptors for the National Qualifications Framework. Pretoria: SAQA.

Staver, J.R. (2007). Teaching science. Geneva: Educational Practices Series, The International Academy of Education (IAE) and the International Bureau of Education (UNESCO).

Tao, G. and Gunstone, R.F. (1999). The process of conceptual change in force and motion during computer-supported physics instruction. Journal of Research in Science Teaching, 36(7), 859-882.

Vosniadou, S. (1994). Capturing and modelling the process of conceptual change. Learning and Instruction, 4(1), 45-69.

Whitaker, R.J. (1983). Aristotle is not dead: student understanding of trajectory motion. American Journal of Physics, 51(4), 352-357. 